\title{
LA GEOLOGÍA SINIESTRA DEL AMOR EN El pasado de Alan Pauls*
}

\author{
Alexis Candia Cáceres**
}

\section{Resumen}

Este artículo propone una revisión de la función del amor en El pasado de Alan Pauls. Para esto, se plantea leer la relación sentimental de Sofía y Rímini a partir de dos conceptos que resultan fundamentales para interpretar la novela: "el amor siniestro" y la "geología del amor". Ambas nociones resultan claves para desentrañar la importancia, los alcances y el sentido de la exploración amorosa en el texto de Pauls. Asimismo, se realizan una serie de conexiones intertextuales necesarias para la comprensión del fenómeno amoroso en la novela.

Palabras clave: Alan Pauls, El pasado, "amor siniestro", "geología del amor", intertextualidad.

\section{THE SINISTER GEOLOGY OF LOVE IN El PASADO of Alan PaUls}

\begin{abstract}
The article proposes a review of the role of love in El pasado of Alan Pauls. For this, it is proposed to read the romantic relationship of Sofia and Rimini from two concepts that are essential for interpreting the novel: "the sinister love" and "geology of love." Both notions are key to unravel the importance, scope and meaning of loving exploration summit Alan Pauls's novel. In addition, this article proposes a series of intertextual connections necessary for understanding the phenomenon of love in the novel.
\end{abstract}

Keywords: Alan Pauls, El pasado, "sinister love", "love geology", intertextuality.

Recibido: 25-02-2014

Aceptado: 13-05-2014

* Proyecto Postdoctorado 2012 núm. 3120104: Las mil formas de Venus en la narrativa hispanoamericana contemporánea, financiado por el Fondo Nacional de Ciencia y Tecnología, Fondecyt. Investigador Responsable: Iván Alexis Candia Cáceres.

** Chileno, Doctor en Literatura, Investigador del Centro de Estudios Avanzados (CEA) de la Universidad de Playa Ancha, Valparaíso, Chile. ivan.candia@upla.cl 
"Sombra final se perderá, ligera./ No nos une el amor sino el espanto; / Será por eso que la quiero tanto"

Borges.

El pasado (2003) de Alan Pauls, libro ganador del XXI Premio Herralde de Novela, realiza un elaborado estudio sentimental de las relaciones de pareja en la Argentina del período finisecular. Pauls despliega una seductora e inquietante representación del rol que tiene el amor en la vida de una pareja de amantes, Sofía y Rímini, los que, luego de doce años de relación, deciden poner término a una pasión que acaricia la perfección. A partir de ello, ambos emprenden una larga travesía en la que deben enfrentar sus deseos, carencias, sufrimientos e iluminaciones. El pasado despliega una mirada que sigue, fundamentalmente, el trayecto de Rímini, quien se internará por los laberintos de la exploración amorosa, intentando formular una ecuación que elimine a Sofía como factor ascendente en su trayecto vital. Sofía, quien nunca podrá rehacer del todo su vida, reaparecerá espectralmente para reivindicar su "derecho" al amor de Rímini. De allí que el propio Pauls defina a El pasado como una novela de post pasión: "Mi libro trata sobre lo que queda de la pasión, una vez que ésta se extingue" (Encuentros digitales).

La crítica ha abordado la novela a partir de tres perspectivas: la serie de conexiones intertextuales de El pasado, el cruce de cuerpo y enfermedad en el texto y la exploración del fenómeno erótico-amoroso del mismo. En primer lugar, es posible considerar el artículo de Elena Donato titulado "Marcel Proust y Alan Pauls: correspondencias en El pasado " trabajo que explora los mecanismos intertextuales, las técnicas novelescas y las estructuras literarias que Pauls toma de En busca del tiempo perdido. La misma autora establece en "La traducción como invención de contemporaneidad. Sobre El pasado de Alan Pauls" el eje central que tiene esa actividad en el desarrollo del texto y cómo el autor produce contemporaneidad, es decir, traduce a los clásicos en el interior del texto. Donato piensa en la traducción de El pasado de las obras de Marcel Proust, Henry James, Dante Alighieri y Sigmund Freud. En segundo lugar, se puede situar "Enfermedad y puesta en abismo en El pasado de Alan Pauls" de Ignacio Lucia, texto que explora el funcionamiento del "Sick Art" de Jeremy Riltse como "órgano de reflejo" en el desarrollo de una trama que se erige como una pieza narrativa 
en la que la enfermedad sintetiza narración y arte. Además, es factible considerar los aportes de Verónica Sager, quien realiza una revisión de cuatro novelas del autor argentino, focalizando su interés en $\mathrm{El}$ pasado. Sager establece la construcción fisiológica de esta novela, relato que, en su perspectiva, está marcado por las “[...] tensiones entre lo interior y lo exterior, lo orgánico y lo inorgánico, la salud y la enfermedad" (Sager 1). En tercer lugar, Elena Donato destaca cómo El pasado puede ser leída a partir de la traducción del sentir amoroso: "Así, la novela de Pauls es un tratado de la pasión amorosa, sólo a condición de que se entienda el amor como un problema de traducción" (Donato, "La traducción" 5). En esta misma dirección, se puede incluir la reseña "Gordura" que Ignacio Echevarría publicó en el suplemento Babelia del diario español El País. Para Echevarría, El pasado es tanto una historia de amor como de horror. Echevarría establece que la novela aborda las posteridades del amor, sus tiranías, "[...] de quienes militan en él como en una religión, de su tendencia a constituirse en destino y doblegar el tiempo en una suerte de "oceánica continuidad sentimental" (Echevarría). Rodrigo Fresán plantea, a su vez, que "El pasado es la más grande y terrible historia de amor jamás contada" (Cit. en Aliaga 9). Alejandro Aliaga realiza, por último, un análisis de El pasado a partir del cruce de la teoría del amor y del arte, proponiendo que ambos son organismos enfermos en permanente mutación.

La "geología siniestra del amor" posee dos directrices que resultan fundamentales para comprender la relación de Sofía y Rímini. Revisemos la primera. Etimológicamente, geología proviene del griego y significa estudio de la Tierra. Se trata de una ciencia que investiga la forma del planeta. A partir de ello, es posible comprender que se trata de una disciplina que estudia los extensos períodos de constitución de la estructura interna de la Tierra. En suma, el componente temporal juega un rol fundamental, tal como lo hacer ver la analogía que Sofía traza respecto del amor que la une al traductor argentino:

Venimos de tan lejos, Rímini. Tenemos millones de años. El nuestro es un amor geológico. Las separaciones, los encuentros, las peleas, todo lo que pasa y lo que se ve, lo que tiene fecha, 1976, todo eso tiene tanto sentido como una baldosa quebrada comparada con el temblor que lleva milenios haciendo vibrar el centro de la tierra. (507, cursivas de Pauls) 
La "geología del amor" consiste en una pasión que se extiende por varios años e incluso décadas y que tiene una compleja y vasta historia. Al igual como sucede con el objeto de estudio de la geología, la Tierra, el amor de Rímini y Sofía se despliega hacia El pasado y se proyecta hacia el futuro, erigiéndose, en definitiva, como una historia sin fin o al menos como una historia que no tiene señales de un término siquiera distante.

La construcción amorosa de El pasado transgrede las concepciones propuestas por algunos de los principales teóricos del sentir amoroso de la segunda parte del siglo XX: Roland Barthes y Anthony Giddens. En Fragmentos de un discurso amoroso (1977) Barthes propone que el amor es finito, posee una trayectoria que da paso a lo que el teórico francés denomina como el errabundeo:

Aunque todo amor sea vivido como único y aunque el sujeto rechace la idea de repetirlo más tarde en otra parte, sorprende a veces en él una suerte de difusión del deseo amoroso; comprende entonces que está condenado a errar hasta la muerte, de amor en amor. (82)

Asimismo, Pauls se pone a contrapelo del "amor confluente" propuesto por Giddens, conceptualización que le sirve al teórico inglés para caracterizar el funcionamiento del amor en el período posterior a los movimientos sociales de la década de 1960. En La transformación de la intimidad. Sexualidad, amor y erotismo en las sociedades modernas el sociólogo británico sostiene que el "amor confluente" explica el surgimiento de una sociedad occidental marcada en el plano familiar por las separaciones, debido a que: "[...] choca con las expresiones "para siempre" "sólo y único" (63). Así, Giddens plantea que el "amor confluente" no considera a una "persona especial" sino a una "relación especial". Asimismo, establece que esta clase de sentir amoroso incluye el arte erótico: "[...] en el núcleo de la relación conyugal y logra la meta de la realización de un placer sexual recíproco" (64).

A pesar de que el trayecto de Rímini se enmarca dentro del errabundeo durante parte importante de la novela, el retorno a los brazos de Sofía hacia el final del texto establece un punto de quiebre con la trayectoria barthesiana, transformándose, más bien, en un sentir que es acrisolado en el transcurso del texto. No se puede pasar por alto, además, que la pareja termina construyendo un amor que, a pesar de los múltiples conflictos que experimenta, termina por consolidar la idea de una 
"persona especial". En El pasado el amor tiene nombre propio. A ello es necesario sumar que, si bien el erotismo está presente en el amor de Sofía y Rímini, no juega un rol fundamental. Lejos del ardor sexual que Rímini experimenta con Nancy o Vera, la relación con Sofía asume a la sexualidad como un componente secundario en el entramado emocional.

La representación del amor en El pasado puede ser explicitada a partir de los planteamientos que formula André Breton. En La llama doble Octavio Paz plantea que el líder del surrealismo asume una posición subversiva y tradicional sobre el fenómeno amoroso debido a que, en un momento histórico marcado por la liberación sexual de los "locos años veinte", Breton aboga por un amor distinto: "Fue ejemplar que en los momentos de la gran desintegración moral y política que precedió a la segunda guerra mundial, Breton haya proclamado el lugar cardinal del amor único en nuestras vidas" (140). El gesto de Breton es útil para este estudio porque Pauls reitera la posición del surrealista francés. En medio de una época de enorme apertura erótica, que sigue al periodo de contracción que marca la irrupción del Sida en la década de 1980, Pauls aboga por un amor único. Así, regresa al pasado para reactualizar una forma de querer desestimada por Giddens: el "amor romántico", es decir, una compenetración sentimental que: “[...] presupone una comunicación psíquica, un encuentro de espíritus que es de carácter reparador" (50). El "amor romántico" se proyecta hacia un sujeto único, persiguiendo la absorción y, finalmente, la integración con el otro. Ciertamente, resulta interesante considerar, además, que esta clase de sentir amoroso concibe que la mujer tenga un papel activo en la cristalización del vínculo sentimental. Esta concepción de lo femenino es central para analizar El pasado debido a que es la determinación de Sofía la que permite consolidar el "amor geológico" hacia el final de la novela: "La heroína alcanza y funde el corazón de un hombre, que es inicialmente indiferente y lejano a ella cuando no abiertamente hostil. La heroína produce así activamente el amor" (51).

La concepción del "amor geológico" se puede entender, además, a partir de la mirada de uno de los principales poetas y ensayistas latinoamericanos: Octavio Paz. El autor de El laberinto de la soledad, quien fue influido por las posiciones de los surrealistas, asume una visión que está en la línea con lo planteado por Breton: "El amor es una atracción hacia una persona única: a un cuerpo y a un alma. El amor es elección" (Paz 33). Paz agrega, además, que esta "[...] misteriosa inclinación 
pasional hacia una sola persona" (Paz 34) implica un deseo de completud que se conecta con la persistencia del mito del andrógeno desarrollado por Platón en El banquete. En Una historia natural del amor, Diane Ackerman destaca también que una de las claves del amor romántico: "[...] es el poderoso deseo de ser uno con el amado" (Ackerman 131). Los aportes de Paz y Ackerman contribuyen a entender la fijación de Sofía por mantener y luego recobrar el amor de Rímini, único sujeto con el que, al fin y al cabo, podrá forjar un amor permanente.

La segunda directriz que emerge del tratamiento del amor en El pasado es la presencia de lo siniestro. No se puede soslayar que la novela de Pauls no tiene por objetivo concentrarse en la combustión del amor sino en sus ruinas y, en esta línea, Sofía irrumpirá en la vida de Rímini como una "mujer-monstruo" que, en múltiples niveles, detonará bombas cuyas ondas expansivas demolerán la vida de su antigua pareja. Bajo esta perspectiva, Sofía materializará una de las concepciones centrales del pintor que admira hasta el extremo, Riltse, cuando éste plantea que el amor no se asocia con la magia o la seducción sino con el espanto. Sofía plasma "El espanto del amor" propuesto por el autor de El agujero postizo, es decir, da forma a un "amor siniestro". Al hablar de "amor siniestro" estoy pensando en el cruce de dos teorías que son claves para entender la relación de estos amantes: la noción de amor de Kristeva y "lo siniestro" de Freud.

En Historias de amor Kristeva plantea que el amor es un vértigo de la identidad y de las palabras: "[...] el amor es, a escala individual, esa súbita revolución, ese cataclismo irremediable del que no se habla más que después. En el momento no se habla de. Se tiene simplemente la impresión de hablar al fin, por primera vez, de verdad" (Kristeva 3). Ahora bien, Kristeva sostiene que el vértigo y el cataclismo que implica el amor pueden transformarse en un desenfreno que incluso puede llevar al crimen del amado:

[...] el amor que llamamos loco se compagina sin embargo muy bien con una lucidez aguda, superyoica, feroz, aunque es el único que puede, provisionalmente, interrumpirla. Himno a la entrega total al otro, ese amor es también, y de una manera casi igualmente explícita, un himno a la capacidad narcisista a la que puedo incluso sacrificarlo, sacrificarme. (Kristeva 1) 
Las ideas de Freud son interesantes al considerar la forma en que Sofía irrumpe en la vida de Rímini. Freud sostiene que lo siniestro (Unheimlich) es un concepto: “[...] próximo a lo espantable, angustiante, espeluznante" (Freud 342). Desde la perspectiva del psicoanálisis los impulsos emocionales son convertidos en angustia por la represión. Así, Freud asume que lo angustioso es aquello reprimido que retorna. A partir de una nota de Schelling -ampliada y precisada por el fundador del psicoanálisis- lo siniestro pasa a ser "[...] todo lo que debía haber quedado oculto, secreto, pero que se ha manifestado" (Freud 344). Y en esa aproximación de lo siniestro, esta sensación no emerge desde lo extraño ni de lo novedoso sino más bien es: “[...] algo que siempre fue familiar a la vida psíquica y que solo se tornó extraño mediante el proceso de su represión" (Freud 338).

Por último, es indispensable consignar que en el artículo se establecen una serie de conexiones intertextuales que buscan interpretar diversos episodios de la novela. La exploración de alusiones ${ }^{1}$ a La divina comedia, El jactancioso de Francis Scott Fitzgerald, La historia de Adela H. de François Truffaut, Torrentes de amor de John Cassavetes, entre otras, es fundamental para explicar los alcances de la propuesta amorosa de El pasado.

\section{El amor como obra de arte}

Pauls inicia el relato desde las cenizas en las que se ha convertido el vínculo de Rímini y Sofía. A dos años del fin de la relación, Rímini recibe una carta de Sofía que narra el suicidio de Jeremy Riltse, creador del Sick Art, artista por el que ambos experimentan devoción. Rímini ha reiniciado su vida con Vera y ha desplegado ingentes esfuerzos para dejar atrás a Sofía. A partir de la llegada del mensaje, el narrador suspende la historia de Vera y se concentra en narrar el amor idílico de Rímini y Sofía:

Creían en el modo en que se amaban, y esa creencia era más fuerte que cualquier naturaleza [...] Eran arrogantes y modestos, altivos y extraordinariamente serviciales. No compartían sus problemas con nadie [...] pero el pequeño departamento de Belgrano $\mathrm{R}$ no tardó en convertirse en la clínica sentimental [...] Eso era quizá lo único de lo que

1 Considero las alusiones en los términos que plantea Gérard Genette en Palimpsestos. La literatura en segundo grado, es decir, un enunciado cuya plena comprensión supone la percepción de su relación con otro enunciado al que remite necesariamente tal o cual de sus inflexiones, no perceptible de otro modo. 
después, una vez terminadas las "consultas", en privado, aceptaban jactarse: monógamos, conservadores, partidarios de una disciplina amorosa que exigía agua y aire y luz diarias. (Pauls, El pasado 48-49)

Pauls construye un amor capaz de soportar los envites del tiempo, la abulia, el rechazo o cualquier otra amenaza. De ahí que Frida Breitenbach, la terapeuta que ejerce como mentora de Sofía, sostenga lo siguiente: “Eran tan hermosos. ¿Cuántos años tenían? ¿Diecisiete? ¿Dieciocho? Me acuerdo de que la primera vez que Sofía te trajo a Vidt pensé: "Son tan hermosos que habría que desfigurarlos" (Pauls, El pasado 273). Sofía y Rímini sienten que comparten un amor absoluto, que está mucho más allá de las circunstancias y problemáticas cotidianas que experimenta una pareja. Superan la infidelidad de Sofía, los vaivenes sentimentales de Rímini, las alteraciones de sus intereses personales, el enfriamiento de la relación, el aborto e incluso la primera separación. En esta dirección, se sitúan las apreciaciones de Alejandro Aliaga en Mutaciones de la postpasión y el arte enfermo en El pasado de Alan Pauls: "Porque, como muchas parejas, ellos también [...] fueron protagonistas de traiciones, engaños y situaciones límites en la vida de una pareja [...] Sin embargo, ellos tenían la capacidad de no sucumbir a estos sucesos" (47). No deja de ser interesante, en este sentido, el quiebre sui generis que experimentan a mediados de su noviazgo. Lejos del dolor o el resentimiento que involucra una ruptura, Sofía y Rímini más bien parecen tomar un descanso para acrecentar el ardor amoroso.

Ahora bien, la idílica relación de Sofía y Rímini está cruzada por la imposición de la estrategia de la memoria que despliega Sofía con el objetivo de inocular, primero, y cristalizar, después, el amor. Sofía piensa que la generación de memorias es el mecanismo idóneo para fortalecer las relaciones sentimentales:

[...] el recuerdo del amor era la unidad mínima del amor, la nervadura que permitía reconstruir toda la hoja, y la hoja con su flor, y la planta entera, y no solo la planta y su lugar en la tierra sino todo el ecosistema del que la planta era, en última instancia, el fruto. (539-540)

La visión de Sofía se entronca con la mirada que entrega Diane Ackerman al afirmar que: "El amor es el recuerdo de algo pasado, un reencuentro con la felicidad perdida" (Ackerman 164). El deseo 
de consolidación del amor llevará a Sofía a producir recuerdos que le permitan mantener una posición soberana sobre Rímini. En esta dirección, es posible considerar las fotografías y, sobre todo, los mensajes que le escribe para fortalecer el interés de Rímini: "Cada mensaje era un bálsamo, una descarga de felicidad, la pequeña dosis de una droga absoluta, el amor que sentía por Sofía, revitalizaba su adicción cuando Rímini menos se lo esperaba, o cuando la costumbre [...] le había hecho creer que podría abstenerse de ella" (23).

Bajo esta perspectiva, es posible leer este racconto de El pasado a partir de la trayectoria amorosa propuesta por Barthes y, específicamente, por la voluntad de Pauls de reconstruir el momento del "Encuentro" entre los amantes. En la primera parte de la novela Pauls plasma el tiempo feliz que siguió al primer rapto: "[...] viene entonces una serie de encuentros (citas, conversaciones telefónicas, cartas, pequeños viajes), en el curso de los cuales "exploro" con embriaguez la perfección del ser amado, es decir la adecuación inesperada de un objeto a mi deseo: es la dulzura del comienzo" (Barthes 80). Sofía y Rímini dan forma a un amor soberano, autosuficiente, inmune al contagio de la miseria y la muerte. Durante doce años se dedican a depurar el sentir amoroso hasta construir lo que, en la perspectiva de Sofía, es: “[...] una obra de arte” (Pauls, El pasado 58).

El pasado reflexiona sobre la naturaleza, los límites, las fortalezas y las debilidades del amor. Entre las múltiples aproximaciones que realiza del fenómeno amoroso, resulta interesante la analogía que traza con un tejido biológico que admite el paso preferencial de ciertas sustancias: las membranas. El narrador emplea la noción de "las membranas del amor" para subrayar que éstas: “[...] son frágiles; el roce más fortuito puede desgarrarlas" (Pauls, El pasado 35). Esta cavilación resulta interesante debido a que el inicio del fin de la relación de Rímini y Sofía pasa por un minúsculo roce que genera un abismo entre ambos: el mensaje de Sofía que Rímini decide no leer. A partir de ese punto, se genera una crisis que tiene que ver con el hecho de que Rímini separa aguas con Sofía en cuanto a que abandona la militancia de la memoria. La disolución del sentir amoroso se ve afectada, también, por la noción evolucionista que establece que una vez alcanzada la perfección solo es posible encontrar la extinción, teoría que, por lo demás, es propuesta por el propio autor:

Sofía y Rímini se separan porque la relación amorosa que los une, llega a una perfección de obra de arte. Y las obras de arte 
son geniales para contemplar pero nadie puede vivir dentro de una. Es un poco lo mismo que pasa con las especies que llegan a un estado evolutivo de perfección y después no pueden si no extinguirse. (Encuentros digitales)

Cuando Rímini y Sofía se dan cuenta de que la relación ha llegado a su fin, optan por escenificar una resolución que esté a la altura de su amor: una armónica separación que contraviene el curso corriente de los desenlaces amorosos y que, además, apunta a superar al primer quiebre. Al inicio la separación funciona en los términos que desea la pareja, sin embargo, existe un punto que genera un choque entre ambos: la repartición de fotografías. Mientras Sofía quiere que cada uno conserve una parte de las fotos, Rímini opta por evitar ese proceso, Pauls sostiene que: “Lo que pasa es que Rímini tiene la política del olvido, ha decidido que lo único que lo puede salvar es el olvido. Mientras que Sofía es una militante de la memoria" (Salazar). A estas alturas parece evidente que la situación se escapa al control y a las expectativas de Sofía. Lo anterior, responde a que ella considera que esta nueva separación constituye un simple paréntesis en su amor, un trazo más de la obra de arte que está delineando junto a Rímini. Pauls enfoca el quiebre de la siguiente manera: "A partir de ello, se genera un quiebre que aparentemente es irreparable. Mientras Rímini apunta a dejar atrás lo antes posible su vida con Sofía, ésta última hará todo lo que esté a su alcance por seguir recordándole que solo ella es y puede ser la soberana de su sentir amoroso" (Pauls). No deja ser interesante que el autor subraye el carácter aparente que ostenta el quiebre debido a que pone de manifiesto cómo el deseo de ruptura está sustentado en la voluntad de Rímini y no en la de Sofía, la que jamás aceptará el fin de la historia de amor. Incluso años después del cierre amoroso seguirá manteniendo la esperanza de que su vínculo con Rímini solo se encuentra en un paréntesis y, en ningún caso, ante un punto final. En este sentido, se puede considerar la afirmación de Giddens en orden a que: "Cuando una relación termina, incluso para quién es el desencadenante y no la persona abandonada, puede persistir la imagen del otro, los hábitos asociados con el otro y las expectativas de que se produzca una reconciliación pueden persistir muchos años después" (Giddens 99). 


\section{Ruinas circulares}

El pasado cuenta con una serie de relaciones intertextuales que son fundamentales para comprender el desarrollo del texto. De las múltiples conexiones que presenta la novela me interesa detenerme en las alusiones que es posible detectar en Sofía y Rímini. La historia de la discípula de Breitenbach puede ser leída a partir de la experiencia de Adela H., vida que es llevada al cine por François Truffaut en La historia de Adela $H$. Truffaut filma diversos episodios de la vida de Adela Hugo, hija menor del escritor francés, que atraviesa por una experiencia amorosa límite debido a su ardiente y no correspondido deseo por el teniente Pinson. El último episodio de El pasado sintetiza la historia de la mujer:

Adela lo dejó absolutamente todo para emprender sola los viajes más extraños y, dada la época, segunda mitad del siglo XIX, sin duda menos recomendables para una mujer de apenas treinta años, primero Halifax, Nueva Escocia, Canadá, donde se había enterado de que tenía asiento el regimiento en el que revistaba Pinson, [...] ese amor solitario que le lleva a mentir, a vestirse de hombre, a cambiar de identidad, a hacerse pasar por Leopoldine, su hermana muerta, a contratar a un hipnotizador para arrancarle a su amado dormido el voto de amor que se obstina en negarle despierto, todo eso para sostener el lema del que no la distraerán el fracaso, ni el sufrimiento, ni el desprecio, ni siquiera el más profundo desquicio mental, sino la muerte: el amor es mi religión. (Pauls, El pasado 526, cursivas mías)

El amor es mi religión constituye un mantra para Sofía que da sentido a su relación con Rímini. Así, Sofía asume la noción del "exceso de amor" que implica un despilfarro sentimental que viene a ser la estrategia idónea para conquistar y reconquistar a su antigua pareja. El pasado explicita la relevancia que tiene la cinta en la vida de Sofía al narrar la ocasión en que ella va a ver la película con Rímini. El film conmueve a Sofía hasta el punto de que es incapaz de terminar de ver la producción cinematográfica: "Entonces Sofía se estremeció, como electrizada, y se puso a llorar en silencio. Lloró tanto y de una manera tan continua que al poco tiempo [...] Rímini [...] de tanto estrecharla ya tenía los antebrazos completamente empapados" (534). El detonante de la reacción de la mujer es una afirmación de Adela que desnuda las concepciones románticas de la propia Sofía: "Puedo aprenderlo todo 
sola, por mi cuenta, pero para amar lo necesito a él" (534). Sofía asume, entonces, que la comunión amorosa solo la puede lograr en el cuerpo de Rímini. De allí que todas sus relaciones posteriores conduzcan a un fin insoslayable: el fracaso.

El episodio de La historia de Adela $H$., que acaece al inicio de la relación de Sofía y Rímini, anticipa y determina el desarrollo del libro. Al igual que Adela, quien solo puede consumar su amor en los brazos del teniente Pinson, Sofía solo puede cristalizarlo con Rímini. Pauls opera narrativamente en relación a lo que Borges denominó como la primitiva claridad de la magia. La novela se organiza a través de un orden diverso, lúcido y atávico, donde se profetizan los pormenores y se postula “[...] un vínculo inevitable entre cosas distantes, ya porque su figura es igual -magia imitativa, homeopática- ya por el hecho de una cercanía anterior -magia contagiosa-" (Borges 88). Borges cree que la novela debe ser: "[...] un juego preciso de vigilancias, ecos y afinidades. Todo episodio, en un cuidadoso relato, es de proyección ulterior" (Borges 90). La historia de Adela $H$. anuncia la vida de Sofía y, en consecuencia, le hace imposible renunciar al amor de Rímini. Si Sofía se conmueve tanto con la historia de Adela es porque está contemplando su propio futuro.

Rímini es un personaje que está signado por su apellido, apellido que remite a la ciudad italiana recordada por la historia de dos amantes adúlteros que acaban en el segundo círculo del infierno: Paolo y Francesca da Rímini. Pauls dialoga con La divina comedia conectando, en primer lugar, la idea del amor absoluto de la pareja italiana con la argentina y, en segundo lugar, alterando el vínculo que se produce entre amor y lectura. Mientras en El pasado el fin de la lectura de los mensajes de Sofía produce el ocaso de la relación amorosa, en el poema de Alighieri se produce el efecto contrario:

Leíamos un día por pasatiempo las aventuras de Lanzarote, y de qué modo cayó en las redes del amor: estábamos solos y sin abrigar sospecha alguna. Aquella lectura hizo que nuestros ojos se buscaran muchas veces y que palideciera nuestro semblante; mas un solo pasaje fue el que decidió de nosotros. Cuando leíamos que la deseada sonrisa de la amada fue interrumpida por el beso del amante, éste, que jamás se ha de separar de mí, me besó tembloroso en la boca [...] aquel día ya no leímos más. (23) 
Pauls produce una inversión jerárquica respecto del procedimiento de Alighieri. Una vez que Francesca y Paolo comienzan a amarse abandonan la lectura, en cambio, cuando Rímini deja de leer los mensajes de Sofía se gesta la destrucción. La expansión de la entropía produce una metamorfosis en el rol de Sofía en la relación sentimental, la que pasa de ser sujeto de adoración a una amenaza para la nueva vida que decide llevar adelante Rímini.

Donato propone una tercera conexión entre El pasado y el Canto V de la Comedia que tiene que ver con el lugar a donde conduce el amor de los amantes: el infierno. No podemos olvidar que el cuerpo central de la novela es la narración de la post pasión y, en este sentido, el vínculo entre Rímini y Sofía parece signado por un viaje infernal:

El pasado es un incesante círculo por el que sus personajes son arrastrados como por una borrasca infernal. Al igual que en el segundo círculo dantesco, sus personajes son carnales pecadores que la razón somete al deseo y su más trágica protagonista es la Francesca da Rímini abrazada a su amante que enardecida por una lectura hace del amor su propio infierno. (Donato, "La traducción...", cursivas de Donato)

Bajo esta perspectiva, es necesario situar la transformación que experimenta Sofía, transformación que la lleva a asumirse como "[...] la mujer-monstruo, la mujer-cuchilla" (505). Pauls trabajó durante cinco años en El pasado y, en buena parte de ese periodo, escribió el texto con el título de La mujer zombie. En una entrevista Pauls menciona que la idea original de la novela proviene del siguiente telegrama mental: "Mujer muerta vuelve de la muerte para enloquecer al hombre que amó" (Sanguinetti). Pauls explica el génesis narrativo de El pasado : "La mujer zombie me sirvió mucho para concentrarme en la idea de que el personaje de Sofía era un poco una muerta viva, para darle un carácter espectral" (Salazar). A partir de esto, es posible leer la relación de Sofía y Rímini desde el "amor siniestro". La pasión de Sofía puede ser analizada no solo como un himno a la entrega total sino como un amor desenfrenado que termina por socavar las bases de la nueva vida de Rímini. Más aun cuando ésta invade de manera espectral el espacio de su antiguo amante para arruinarle las posibilidades de generar una historia distinta al pasado. Sofía es todo aquello que debía haber quedado oculto, secreto, reprimido, pero que 
se ha manifestado de manera espeluznante en la vida de Rímini y que desencadena catástrofes que acaban por imponer lo que Kristeva denomina como un "amor loco". De los numerosos momentos en que se proyecta la sombra de Sofía, es necesario detenerse en una triada de sucesos: la tragedia de Vera, la pérdida de la memoria de Rímini y el secuestro de Lucio.

Tras el término de su unión con Sofía, Rímini comienza una relación con una hermosa, joven y celópata mujer llamada Vera. La relación es bastante más ardiente que el vínculo que mantuvo con Sofía y coincide con la época de mayor pasión de la vida de Rímini, época marcada por la adicción a la masturbación, la cocaína y la traducción. Paralelamente a la relación de Rímini y Vera corre el vínculo soterrado que Sofía todavía cree tener con el traductor argentino y que descansa, sobre todo, en la obsesión de repartir las fotografías. La reticencia de Rímini detona la ira de Sofía, quien no puede concebir el trato que le da el hombre con el que compartió más de una década.

¿Doce años estuvimos juntos y no tenés tiempo para mí? ¿Cómo podes ser tan basura, tan mierda? ¿Te creés que esto te va a salir gratis? ¿Qué vas a seguir así, por la vida, libre, como si nada? ¡Vas a pagar, Rímini! [...] lo besó. Saltó sobre él, lo agarró de las orejas, una mano en cada una, como si fuera a arrancárselas, y le escarbó la boca con los labios y la lengua hasta abrírsela, y una vez sorteada la doble barricada de dientes Rímini sintió que una ráfaga de aire frío [...] le escarchaba la boca y la garganta. (232)

La contemplación del beso es un golpe particularmente duro para una celópata como Vera, quien presencia la escena desde la vereda opuesta a la ex pareja de amantes. Lo anterior, responde a que el mayor temor de la mujer se ve confirmado, lo que le produce una conmoción que la lleva a cruzar desprevenidamente la calle. Tras librarse de Sofía, Rímini solo puede contemplar el siguiente episodio: "[...] sintió un impacto sordo y después de un segundo de desconcierto sorprendió a Vera en el aire [...] oyó un estrépito de chapa, vidrios rotos, y cuando Rímini bajo los ojos ya todo había terminado: Vera yacía boca arriba en el pavimento, inmóvil" (Pauls, El pasado 233).

Uno de los aspectos más llamativos de El pasado es la extraña amnesia que experimenta Rímini después de la muerte de Vera. Rímini padece una 
pérdida de memoria selectiva que lo conduce a olvidar los idiomas. De la traducción obsesiva que realiza en la época con Vera pasa a la incapacidad absoluta de comprender lenguas en su matrimonio con Carmen. El pasado da escasas luces acerca de los factores que motivan la enfermedad. Sin embargo, seis años después de la publicación de la novela Pauls retoma a sus protagonistas en un cuento titulado "Ex" ${ }^{2}$, incluido en Excesos del cuerpo. Ficciones de contagio y enfermedad en América Latina compilado por Nathalie Bouzaglo y Javier Guerrero. Allí, el autor argentino narra el encuentro de Rímini con el nuevo novio de Sofía, "El lastimado", quien le exige que vuelva con ésta: "Lo pensé bien", dijo. "Es la única posibilidad. O vuelven o te mato". (68). Para "El lastimado", Sofía, Rímini y él mismo están intoxicados y la única manera de restablecer el orden es que los antiguos amantes retomen el amor que habían abandonado. Sofía: "No podía olvidar. Eso era todo. Y sufría porque su memoria, que era implacable, no era lo suficientemente poderosa para impedir esa atrocidad máxima: que vos siguieras olvidando" (74). Así, es posible sostener que Sofía y Rímini han establecido una simbiosis debido a que la interacción que se ha producido entre ambos es estrecha y persistente, aun cuando son individuos de distinto género. En el marco del abismo que se ha producido entre ambos, Sofía produce la amnesia de Rímini y, a su vez, Rímini incentiva con su desinterés por El pasado la militancia en el recuerdo de Sofía. De hecho, Bouzaglo y Guerrero sostienen que: "Sofía no es capaz de dejarlo morir y, paradójicamente, la enfermedad de ella -que radica en no poder olvidar su historia pasada con Ríminiproduce a su vez el padecimiento de él, su desmemoria" (29-30).

La irrupción más siniestra de Sofía se produce cuando conoce al hijo de Rímini: Lucio. Luego de regalarle unas zapatillas acuerda con Rímini una cita para conocer al bebé. Tras una "frustrada" visita a un motel motivada por la súplica de Sofía y el deseo de Rímini de liberarse de su antigua pareja, Sofía secuestra a Lucio. En una carta a Rímini posterior al crimen, Sofía confiesa los motivos del mismo: "Con algo tuyo tenía que quedarme. Algo más, algo mejor que esas pobres lágrimas de leche tibia que me dejaste adentro en el hotel. Qué triste todo, Rímini. Era tan fácil. Estaba tan caliente" (312). El secuestro de Lucio detona una catástrofe en

2 No es azaroso que Pauls titule el relato de esa forma. "Ex" fue una de las alternativas que barajó para titular El pasado: "Ex, que al momento me gustó mucho, me pareció como un logotipo, muy breve, universal, y que no sólo aludía a la condición de ex marido o ex mujer sino a "arrancado de", "separado de" (Salazar). 
la vida de Rímini. No solo porque la visita al motel provoca el término de su matrimonio sino porque Carmen lo obliga a renunciar a sus bienes materiales y, además, a cualquier tipo de acercamiento a su hijo. Cobran especial interés, en este punto del análisis, las palabras de Francis Scott Fitzgerald en El jactancioso cuando sostiene que: "Toda vida es un proceso de demolición"(7). El secuestro de Lucio significa un derrumbe en la vida de Rímini, quien sufre un golpe económico -de hecho se va a vivir a la casa de su padre- $y$, sobre todo, un impacto emocional que lo conduce a un estado de abandono absoluto. Rímini se ve atravesado por la sensación de absurdo, en términos de Camus, debido a que experimenta un divorcio con el mundo que le genera la pérdida de toda esperanza. Lo anterior se aprecia en el estado en que Rímini espera a los potenciales compradores de la casa de su padre:

[...] podía describir el ritmo al que le crecían las uñas, el pelo o la barba, y también la intensidad del dolor que empezaba a despedir su cuerpo. Rímini era el paso del tiempo -la vida desnuda-. Una obra maestra de la inercia, sin dirección ni propósito: vida inmanente, vida en caída libre. (335)

El pasado es una "post secuela" -parafraseando el concepto de Barthesen términos de que una vez dado de baja, oficialmente, el vínculo amoroso, sigue persistiendo: "[...] el largo reguero de sufrimientos, heridas, angustias, desamparos, resentimientos, desesperaciones, penurias y trampas de que soy presa, viviendo entonces sin cesar bajo la amenaza de una ruina que asolana a la vez al otro, a mí mismo" (Barthes 80). Las siniestras apariciones de Sofía generan una pila de ruinas circulares en la vida de Rímini. Sin embargo, a diferencia del modelo barthesiano, el amor no es finito en El pasado, sino que muta, constantemente, reiterándose a sí mismo. Es más, en la misma carta que termina por arruinar a Rímini, Sofía le anticipa el desenlace de su historia al sostener que seguía: “[...] pensando en el día en que por fin puedas rendirte a la evidencia de que me amás y que el amor es una corriente continua" (313).

\section{La geología del amor}

Tras la inmensa cantidad de mal que se infringe el uno al otro, tanto por el "amor siniestro" que prodiga Sofía como por la indiferencia de Rímini, la pareja tendrá un reencuentro que dotará de sentido a "la geología del amor". Las múltiples apariciones espectrales de Sofía llegan 
a su fin cuando auxilia a su antiguo amante en un momento de necesidad y abandono, tanto porque ha perdido sus puntos de apoyo como porque el robo de El agujero postizo de Riltse lo deja en una compleja situación legal. Sofía irrumpe en este momento para pagar la fianza de Rímini y llegar a un acuerdo con Nancy, ex amante de Rímini a la que le había robado el cuadro, a fin de no proseguir con las acciones judiciales. Al salir de la celda Rímini abraza a Sofía y la terapeuta argentina pronuncia la misma palabra en reiteradas ocasiones:

[...] lo repetía una y otra vez, "Basta, Basta, Basta", hasta que Rímini sintió que la voz se adensaba, precipitaba y cambiaba de estado [...] y le entraba directamente en la sangre y empezaba a viajar por él sin apuro, guiada por un solo deseo ciego: llegar hasta su corazón, tomarlo, y fecundarlo. (502)

Sofía no solo susurra una petición sino que formula "un hechizo". A través de un gesto simbolista, Sofía emplea "la alquimia del verbo" -al decir de Rimbaud- para transformar la realidad. Y lo logra. No por nada la novela trabaja con la siguiente concepción: “[...] el amor era en efecto la fuerza alquímica más extraordinaria, la única capaz de transformar la pobreza del mundo en un lujo sublime" (184). Rímini renuncia, entonces, a su política del olvido y retorna a la militancia de la memoria propuesta por Sofía, tal como lo plantea Ignacio Echevarría en "Gordura”, El pasado : "[...] propone una suerte de extremada y tortuosa parábola por medio de la cual se ilustra cómo, a través de la fuerza y la amenaza del amor, de su violencia casi, puede un hombre ser devuelto a su propio relato" (Echevarría). El paso del estado de latencia a reactivación del vínculo de Sofía y Rímini, desafiando la postura de Barthes y Giddens, valida la idea que Pierre-Gilles, ex amante de Riltse, le cuenta a la joven Sofía: "El amor es un torrente continuo" (46), idea que será asumida por Sofía y que, muchos años después, le reitera al propio Rímini en una de sus cartas $^{3}$. En esta dirección, es posible comprender la sensación de Rímini de regresar a un museo donde no existen los estragos del tiempo ni la amenaza de la muerte: “No, no volvía a una casa, ni al amor de una mujer, ni siquiera a un pasado -porque la casa, y el amor de una mujer y hasta El pasado nunca son del todo inmunes a la acción del tiempo. Volvía a un museo" (513).

3 La amplia formación cinéfila de Pauls se aprecia, nuevamente, al trazar una conexión intertextual con una de las afirmaciones más atractivas de Torrentes de amor (1984) de John Cassavetes: "El amor es una corriente. Es algo continuo que nunca se detiene". 
El regreso de Rímini marca el reencuentro con su propia memoria. De hecho, dedica parte importante de su tiempo a revisar y a anotar los centenares de fotografías que durante muchos años no quiso ni siquiera recibir. De esta manera, es posible sostener el triunfo de Sofía en cuanto impone una de las tesis claves de su teoría amorosa.

Tras la exitosa inauguración del bar Adela H. Rímini arrastra a Sofía -en estado de ebriedad- hacia su departamento. Allí hacen el amor "[...] casi dormidos, sin despegarse, frotándose con una ebria indolencia" (547). En medio de un brumoso estado Sofía pronuncia una frase iluminadora "Menos luz, menos luz" (547). A pesar de que el sentido de esa afirmación puede responder a la molestia que genera la luminosidad en una persona ebria, no se puede pasar por alto que la elección de Pauls está aludiendo a la aparente sentencia final pronunciada por Goethe en su lecho de muerte: "luz, más luz", la que, tradicionalmente, se ha interpretado por el deseo de persistir en la búsqueda del conocimiento. La inversión del concepto de Goethe lo entiendo desde la lógica de que Sofía ha pasado de la etapa de búsqueda a la de encuentro y, en consecuencia, a la sensación de saciedad. El regreso de Rímini a su vida le permite alcanzar cierta satisfacción vital. Mientras Sofía comienza a dormir Rímini retoma la revisión de las fotografías que lo había obsesionado en las últimas semanas. En ese instante descubre que Sofía está sangrando:

Iba a taparla [...] cuando vio una línea de sombra que salía de su sexo y serpenteaba en la sábana blanca. Se inclinó y rozó la sábana con la yema de los dedos. Era sangre. Y enseguida, inclinándose un poco más, acercó la cara y pudo verla brotar de la hendidura de su sexo [...] Entonces Rímini entreabrió su bata y vio que también su sexo goteaba sangre. (550-551)

El desangramiento de la pareja tiene al menos dos lecturas. En primer término, se puede interpretar que ésta se acerca a la muerte. En segundo término, se puede entender que Sofía y Rímini se encaminan a consumar la obra de arte anunciada por Sofía: su historia de amor. La segunda explicación se encuentra respaldada por la siguiente afirmación del personaje de la novela Breitenbach: "Sangrar lo justo en el momento justo: ése es el secreto de la inmortalidad" (274). Ambas teorías son complementarias. Pauls cierra la novela con una serie de frases que son concluyentes en este sentido: "Cuando despertó, una luz débil entraba en la persiana. Ningún cambio. Seguían desangrándose" (551). Sofía 
y Rímini se encuentran en el límite que separa la vida de la muerte y preparan, al modo de Riltse, la línea final de su obra de arte, es decir, en la ruta hacia la muerte persiguen la conclusión de una historia que se escribe dos veces -al decir de Marx- a fin de proyectarse hacia la eternidad. Los cruces con La divina comedia vuelven a ser relevantes en este punto. Principalmente, porque el relato de Francesca da Rímini contribuye a explicar el desenlace de El pasado.

Amor, que se apodera pronto de un corazón gentil, hizo que éste se prendara de aquel hermoso cuerpo que me fue arrebatado de un modo que aún me atormenta. Amor, que no dispensa de amar al que es amado, hizo que me entregara al placer de que se embriaga éste tan vivamente que, como ves, no me abandona nunca. Amor que nos condujo a la misma muerte. (22)

Bajo esta perspectiva, no se puede ignorar una de las disquisiciones de Pauls sobre el desenlace de la novela: "La que me suena más familiar [...] es que, al desangrarse, se vuelven lo que siempre fueron, dos amantes platónicos" (Encuentros digitales). Aliaga refrenda la tesis de Pauls:

Rímini y Sofía, al desangrarse hacia el final del relato pasan a ser figuras mitológicas, amantes platónicos, pues al morir encarnan la explicación al origen del amor. Vivos formaban parte de una teoría, pero al morir se hacen particularidad universal: devienen en mito, en el mito del amor perfecto. (71)

Ahora bien, no basta con enunciar la conexión de El pasado y el amor platónico sino que es clave profundizar en qué medida la novela puede ser leída a partir de las concepciones de Platón. Para esto, es clave acudir a El Banquete, texto en el que diversas figuras griegas reflexionan sobre el amor. De los discursos incluidos en El Banquete me interesa la intervención de Sócrates dado que, en su condición de mentor del filósofo ateniense, es quien interpreta sus concepciones. Sócrates establece que el objetivo del amor es la generación y producción de la belleza, ya sea a través del cuerpo o del alma:

Todos los hombres [...] son capaces de engendrar mediante el cuerpo y mediante el alma [...] y si solo en la belleza, la unión del hombre y de la mujer es una producción, y esta producción es una obra divina, fecundación y generación, a que el ser mortal debe su inmortalidad. (Platón 199) 
Al considerar la utilidad de las nociones platónicas no pienso en que Rímini y Sofía sean productores de cuerpos, sobre todo, debido a que tienen una voluntad de esterelidad ${ }^{4}$ sino a que persiguen la inmortalidad del alma. Lejos de cualquier connotación metafísica, Platón vincula esta concepción con la potencia creadora:

Porque los hay que son más fecundos de espíritu que de cuerpo para las cosas que al espíritu toca producir ¿Y qué es lo que toca al espíritu producir? La sabiduría y las demás virtudes que han nacido de los poetas y de todos los artistas dotados del genio de la invención. (Platón 202)

Es claro que Sofía y Rímini no son productores de obras literarias ni artísticas. Más bien se trata de fecundadores de una intensa y compleja historia de amor. ¿Cómo se puede entender, entonces, que Rímini y Sofía busquen y encuentren la inmortalidad del espíritu? Precisamente, porque son capaces de generar un amor que se convierte en una obra de arte y, en esta línea, es posible sostener que el amor es, también, una manifestación artística, tal como lo establece Eric Fromm en El Arte de Amar. Una investigación sobre la naturaleza del amor al sostener que: "[...] el amor es un arte, tal como es un arte el vivir. Si deseamos aprender a amar debemos proceder en la misma forma en que lo haríamos si quisiéramos aprender cualquier otro arte" (16). Bajo esta perspectiva, el final de la novela constituye el punto máximo del misterio del amor; Sofía y Rímini, tendidos desnudos en la cama, luego de haber hecho el amor, yacen entre el sueño y la vigilia, entre la vida y la muerte, simbolizando un relámpago que, al decir de Platón, se erige como la belleza eterna: “[...] increada e imperecible, exenta de aumento y disminución; belleza no es bella en tal parte y fea en cual otra, bella solo en tal tiempo y no en tal otro, bella bajo una relación y fea bajo otra [...] sino que existe eterna y absolutamente por sí misma" (204-205).

En "Ex" Sofía realiza una afirmación que tiene un eco poderosísimo en El pasado . Cuando le cuenta a "El lastimado" que va a conocer a Lucio le dice lo siguiente: "Voy a conocerlo a Lucio y voy a sembrar'. '¿Sembrar qué?'. 'Sembrarme" (75). La importancia de esa sentencia pasa porque sintetiza el modus operandi de Sofía en la medida que busca fecundar en el presente una serie de memorias que, al pasar el tiempo, se anclen en $E l$

4 Ambos rechazan la posibilidad de ser padres. Lo anterior se demuestra al considerar el aborto al que se somete voluntariamente Sofía y la renuncia legal de Rímini a sus derechos paternos sobre Lucio. 
pasado con el objetivo de que germinen en el futuro. Eso es lo que sucede con Rímini y es lo que explica que su retorno restablezca la confianza en la máxima relativa a comprender el amor como un orden superior.

\section{La divina tragedia}

El pasado constituye un tratado de las relaciones sentimentales de fines del siglo XX e inicios del XXI, alcanzando un sitial privilegiado, en este sentido, en el marco de la literatura hispanoamericana. Pauls construye un relato que explora de manera totalizadora el fenómeno amoroso en una pareja de amantes argentinos, focalizando su interés en la dialéctica permanencia / cambio que se produce en el vínculo de Sofía y Rímini. Así, el autor explora la inmutabilidad del amor en los doce primeros años de relación, la dramática transformación que experimenta éste en la etapa de post pasión y, finalmente, el regreso al museo o a la concepción del amor como obra de arte hacia el final del texto.

El recorrido de Sofía y Rímini se puede leer a partir de dos conceptos claves para comprender el devenir de la pareja: el "amor siniestro" y la "geología del amor". El "amor siniestro" permite analizar la metamorfosis que experimenta Sofía en el cuerpo central de la novela, pasando de ser sujeto y objeto del amor de Rímini a la mujer infernal que irrumpe para detonar el horror en su vida y consolidar, en definitiva, el "espanto del amor". La "geología del amor" permite leer la continuidad del sentir amoroso en El pasado . Lejos de la conceptualización propuesta por Barthes y Giddens, Pauls plasma un amor entendido como un torrente continuo. En El pasado el amor puede desfigurarse hasta quedar casi irreconocible pero nunca llega a su fin. Bajo este prisma, se puede entender un desenlace en el que los amantes -desangrándose- pueden caminar hacia la muerte y/o la eternidad.

El pasado se proyecta, en definitiva, como una historia sin fin, vastísima, construida en doce años de pasión, fragmentada y rota en una década de "amor siniestro" y que, a pesar del dolor y la miseria, es capaz de transformarse en una "belleza eterna". 


\section{Referencias bibliográficas}

Ackerman, Diane. Una historia natural del amor. Barcelona: Anagrama, 2000.

Alberoni, Francesco. El erotismo. Barcelona: Editorial Gedisa, 2006.

Alighieri, Dante. La divina comedia. Trad. Enrique de Montalbán. París: Librería Española de Garnier Hermanos, 1894.

Aliaga, Alejandro. Mutaciones de la postpasión y el arte enfermo en El pasado de Alan Pauls. Tesis de Magíster en Letras con mención en Literatura. Pontificia Universidad Católica de Chile. 2006.

Barthes, Roland. Fragmentos de un discurso amoroso. Trad. Eduardo Molina. México DF: Siglo Veintiuno Editores, 1993.

Borges, Jorge Luis. Discusión. Buenos Aires: Emecé Editores, 1964.

Bouzaglo, Nathalie y Guerrero, Javier. "Fiebres del texto - ficciones del cuerpo". Excesos del cuerpo. Ficciones de contagio y enfermedad en América Latina. Comp. Nathalie Bouzaglo y Javier Guerrero. Buenos Aires: Eterna Cadencia Editora, 2009.

Dema, Verónica. “Alan Pauls: "El amor está enfermo desde el minuto uno". Lanación.com.arg. Febrero 2014. Web. [12/2/2014] $<$ http: / / www.lanacion.com.ar/1140344-alan-paulsel-amor-esta-enfermo-desde-el-minuto-uno>

Donato, Elena. "La traducción como invención de contemporaneidad. Sobre El pasado de Alan Pauls". BOLETIN/12 del Centro de Estudios de Teoría y Crítica Literaria (Diciembre 2005): 1-14.

."Marcel Proust y Alan Pauls: correspondencias en El pasado". Fragmentos 37, (jul - dic de 2009): 27-37.

Echevarría, Ignacio. "Gordura". Elpais.es. 6 de diciembre de 2003. Web. [6/12/2013]. <http://elpais.com/ diario/2003/12 / 06 / babelia / 1070671812_850215. html> 
Encuentros digitales. "Alan Pauls". El mundo España. 3 Mar. 2004. Web. 1 Ene. 2013. [3/3/2014]. <http: / / www.elmundo.es / encuentros/invitados / 2004/03/991/>

Freud, Sigmund. Lo siniestro. En Obras completas. Santiago: Pax, 1935.

Fromm, Eric. El Arte de Amar. Una investigación sobre la naturaleza del amor. Argentina: Paidós, 2002.

Genette, Gerard. Palimpsestos. La Literatura en segundo grado. Madrid: Taurus, 1989.

Giddens, Anthony. La transformación de la intimidad. Sexualidad, amor $y$ erotismo en las sociedades modernas. Trad. Benito Herrero Amaro. Madrid: Ediciones Cátedra, 1992.

Kristeva, Julia. Historias de amor. Trad. Araceli Ramos Martín. México: Siglo XXI Editores, 1987.

Kasztelan, Nurit. "39 preguntas a Alan Pauls". No-retornable.com.ar. Agosto 2009. Web. [12/11/2013]. <http: / / www.noretornable.com.ar/v3/entrevista/>

Lucia, Ignacio. "Enfermedad y puesta en abismo en El pasado de Alan Pauls". Actas del II Congreso Internacional "Cuestiones críticas". 2009. Web. [12/11/2013]. <http: / / www.celarg.org/int/arch_publi/lucia_ ignacio.pdf $>$

Pauls, Alan. El pasado . Barcelona: Anagrama, 2003.

. "Ex". Excesos del cuerpo. Ficciones de contagio y enfermedad en América Latina. Nathalie Bouzaglo y Javier Guerrero (Comp.). Buenos Aires: Eterna Cadencia Editora, 2009.

Fitzgerald, Francis Scott. El Jactancioso, Santiago: Zig-Zag, 1969.

Paz, Octavio. La llama doble. Amor y erotismo. México: Editorial Seix Barral, 1994.

Platón. Diálogos. Trad. Patricio Azcarate. Madrid: EDAF, EdicionesDistribuciones, 1984. 
Sager, Verónica. “El pasado". Revista Orbis Tertius 9 (2004): 205-208.

Salazar, Diego. "Alan Pauls existe". Clubcultura.com. Febrero 2014. Web. [17/12/2013]. <http://www.clubcultura.com/ clubliteratura/alanpauls/alan.htm>

Sanguinetti, M. F. "Alan Pauls". Parati.com.ar. Enero 2004. Web. [5/1/2014].<http:/ / www.parati.com.ar/lo-nuevo/ actualidad/alan-pauls/5386.html>

Stefanoni, Andrea y Lapunzina, Damián. "Somos una obra de arte". Radiomontaje.com.ar. Febrero 2014. Web. [14/2/2014]. <http://www.radiomontaje.com.ar/ literatura/pauls.htm>

Truffaut, François. La Historia de Adèle H. Francia: Les Filmes du Carrousse, 1975. 